ORIGINAL PROF-2233

\title{
SMALL BOWEL DIVERTICULAR DISEASE;
} HOW OFTEN WE COME ACROSS IN EXPLORATORY LAPAROTOMY

Dr. Ansar Latif, Dr. Anila Ansar, Col. Dr. Muhammad Qasim Butt.

ABSTRACT... Objectives: 1). To see the prevalence of small bowel diverticulosis in patients presenting with acute abdomen. 2). To know presentation and complications of diverticulosis in teaching hospital in Sialkot region of Pakistan. Introduction: Small bowel diverticular disease may be complicated by small bowel obstruction. Multiple diverticulosis represents an uncommon pathology of the small bowel. Related complications such as diverticulitis, perforation, bleeding or intestinal obstruction, and acute pancreatitis appear in 10-30\% of the patients, increasing the morbidity and mortality rates. This pathology which is uncommon is much higher in our study in patients undergoing exploratory laparotomy in district level hospitals in Sialkot region of Pakistan. Study Design: Prospective and observational. Setting and duration: Combined Military Hospital, Sialkot (June 2005 to August 2010). Islam teaching hospital, Sialkot (September 2010 to September 2012). Methods: 260 consecutive patients undergoing exploratory laparotomy for obstruction, peritonitis, pain and mass abdomen were included in the study. Patient with established cause of obstruction were excluded. The data including demographic information, presentation, operative findings, complications and follow up were entered in structured proforma. Patients with less than three months of followup were also excluded from study. Results: Small bowel diverticuli were encountered in 24 (9\%) out of 260 patients including; 8 (3\%) Meckel's, 9 (3.5\%) jejunal, 3 (1.2\%) duodenal and 4 (1.5\%) Ileal diverticuli. These patients with diverticuli presented as intestinal obstruction, peritonitis, mass abdomen, vague abdominal pain and one patient with fresh bleeding per rectum. The indications of surgery were peritonitis 6 (25\%), intestinal obstruction 13 (54.2\%), abdominal mass 3(12.5\%), nonspecific abdominal pain 1 (4.2\%) and fresh bleeding per rectum of obscure origin 1 (4.2\%). Complications encountered as Intestinal obstruction due to adhesion formation in 8; obstruction due to congenital bands attached to diverticuli in 3; diverticular perforation in 2; peritonitis due to diverticulitis in 2, bleeding from arteriovenous malformation within the jejuna diverticuli in 1 and mass formation due to volvulus in 1 . Three duodenal diverticuli and 4 jejunal diverticuli were found as silent pathologies synchronous with other active pathologies.

Key words: Diverticulum, diverticulectomy, exploratory laparotomy, intraoperative.

\section{Article Citation}

Latif A, Ansar A, Butt MQ. Small bowel diverticular disease; how often we come across in exploratory laparotomy. Professional Med J 2013;20(5): 776-782.

\section{INTRODUCTION}

A diverticulum is a pouch or cul de sac, whether normal or abnormal, leading from a cavity. In the large bowel, diverticula are found commonly, the sigmoid and the descending colon being the favourite locations ${ }^{1}$. Small bowel diverticula occur near the mesenteric attachment. It can be due to traction or pulsion, congenital or acquired, may be true and false, or pseudo-diverticula. True diverticula are composed of all layers of the intestinal wall, whereas false diverticula are formed of the mucosal and submucosal layers. Meckel's diverticulum is a true diverticulum. Diverticula can be classified as intraluminal or extraluminal. Intraluminal diverticula and Meckel's diverticulum are congenital. Extraluminal diverticula may be found in various locations and called as duodenal, jejunal, ileal, or jejunoileal diverticulae ${ }^{2}$.
Jejunal diverticulosis may be associated with many diseases, and were first described by Sir Astley Cooper in 1807. It is a rare lesion of the small intestine seen in $2 \%-2.3 \%$ of small-bowel contrast studies and $1.3 \%-4.6 \%$ of autopsy studies. The disease is clinically significant because of associated potential risk of serious complications. Most cases of duodenal diverticula are observed in patients older than 50 years, while jejunoileal diverticula are commonly observed in patients aged 60-70 years ${ }^{3}$.

Meckel's diverticulum is the most common congenital malformation of the gastrointestinal tract present in $2 \%$ to $4 \%$ of population ${ }^{4}$. It is a true diverticulum; present at usually $30-40 \mathrm{~cm}$ from the ileo-cecal valve. It is the most common cause of bleeding in the pediatric age group. The most frequent complications in adults are obstruction due to the intussusceptions or 
adhesive band, ulceration, diverticulitis and perforation ${ }^{5}$.

Small bowel diverticula are generally asymptomatic, with the exception of Meckel's diverticulum. Main complications include diverticulitis, internal hemorrhage, intestinal obstruction, acute perforation, and pancreatic and/or biliary disease in duodenal diverticula. More acute complications include perforation, peritonitis, bleeding, and fistula formation ${ }^{6}$. Mortality is influenced by patients' age, nature of complications, and timeliness of intervention. Massive gastrointestinal (Gl) bleeding can occur with multiple jejunal diverticulosis; ; and should raise the suspicion for secondary coexisting lesions within the diverticulae, for example, ArterioVenous malformations (AVMs), adenomas, or tumors. Small-bowel bezoars and enteroliths associated with diverticulosis can lead to complications and small bowel obstruction necessitating surgical intervention.

Small-bowel diverticulosis is sporadically observed during conventional small-bowel barium followthrough. Small-bowel diverticula are detected on Gastrograffin/ barium studies in about 2\% of patients, but no contrast leak is usually detected. Ultrasound and computed tomography are frequently used but a specific diagnosis may not always be available. Jejunal diverticula have characteristic findings on $\mathrm{CT}^{9}$.

The treatment of symptomatic and complicated diverticulosis is surgical and this can be achieved either by diverticulectomy or by the segmental bowel resection and anastomosis, especially when there is palpable ectopic tissue, intestinal ischemia or perforation ${ }^{10,11}$.

\section{Methods}

260 consecutive patients who underwent exploratory laparotomy for varied indications but without a definite preoperative diagnosis at Combined Military Hospital,
Sialkot (July 2005 to June 2010) and Islam Teaching Hospital Sialkot ( July 2010 to October 2012) were included in the study.

Detailed history and thorough physical examination was performed; ultrasonography was performed in all patients while CT scan was done in 69 and 36 had Barium contrast studies. The main clinical indications of surgery were peritonitis (94), intestinal obstruction (148), and abdominal mass (11), and nonspecific abdominal pain (14). 4 patients presented with fresh bleeding of obscure origin.

The patients having definitive preoperative diagnosis were not included. . Routine follow up on $5^{\text {th }}$ and $10^{\text {th }}$ postoperative day; and fortnightly follow up done for minimum 3 months for postoperative complications.

Data from both the hospitals was collected and analysed using SPSS version 17.

\section{RESULTS}

Small bowel diverticular disease was diagnosed intraoperatively in $24(9.1 \%)$ patients. The patients age ranged from 10 years to 70 years with mean age of 34 years. The indications of exploration were peritonitis 6 (25\%), intestinal obstruction $13(54.2 \%)$, abdominal mass $3(12.5 \%)$, nonspecific abdominal pain $1(4.2 \%)$ and fresh bleeding per rectum of obscure origin 1 (4.2\%).

Among Meckel' diverticulum, 6 out of 8 cases were found in patients less than 20 years of age while 2 were in elderly patients. All the cases of jejunal diverticulae presented in age group beyond 45 years. Duodenal diverticuli were found in 3 patients as single diverticulum in the $2^{\text {nd }}$ part of duodenum in the age group between 40-55 years. Males were involved more than females 16:8.

Meckel's diverticuli caused intestinal obstruction in 2 patients while 6 patients presented with pain and were 


\begin{tabular}{|l|c|}
\hline Perforated duodenal ulcer & $43(16.3 \%)$ \\
\hline Perforated appendix & $28(10.6 \%)$ \\
\hline Enteric perforation & $39(14.8 \%)$ \\
\hline Tubeculous perforation/strictures/bands & $19(7.2 \%)$ \\
\hline Congenital bands causing obstruction & $21(8.0 \%)$ \\
\hline Small bowel diverticuli \\
Meckel's diverticulum & $24(9.1 \%)$ \\
Jejunal divericuli & $08(3 \%)$ \\
Asyodenal diverticulum & $09(3.4 \%)$ \\
with other pathology & $03(1 \%)$ \\
\hline Volvulus of small intestine & $04(1.5 \%)$ \\
\hline Intussusceptions & $09(3.4 \%)$ \\
\hline Abdominal helmithiasis & $07(2.7 \%)$ \\
\hline Omental phlegmon / cholecystits & $04(1.5 \%)$ \\
\hline Mesenteric ischaemia & $07(2.7 \%)$ \\
\hline Phytobezoars / trichobezoars & $06(2.3 \%)$ \\
\hline Ovarian / adnexal masses & $04(1.5 \%)$ \\
\hline Small intestinal tumours papillomas / lymphomas & $16(6 \%)$ \\
\hline Volvulus of Colon & $04(1.5 \%)$ \\
\hline Ruptured Ectopic Pregnancy found peroperatively & $07(2.7 \%)$ \\
\hline Pancreatic pathologies & $17(6.4 \%)$ \\
\hline Perforated toxic megacolon & $08(3 \%)$ \\
\hline Table-l. Operative findings-260 laparotomies (diagnosis 264$)$ \\
\hline
\end{tabular}

\begin{tabular}{|l|c|}
\hline Meckel's Diverticulum & $8(33.33 \%)$ \\
\hline Jejunal Diverticulum & $9(37.5 \%)$ \\
\hline Duodenal Diverticulum & $3(12.5 \%)$ \\
\hline $\begin{array}{l}\text { Asymptomatic ileal diverticuli synchoronous } \\
\text { with other pathologies }\end{array}$ & $4(16.67 \%)$ \\
\hline \multicolumn{2}{|c|}{ Table-II. Operative diagnosis $(\mathbf{n}=\mathbf{2 4})$} \\
\hline
\end{tabular}

having diverticulitis. Jejuna diverticuli presented as intestinal obstruction due to adhesions in 6 patients while 2 presented as abdominal masses and one patient's diverticulum presented with peritonitis due to perforation. Ileal diverticuli in 4 patients were silent and found synchronous with perforated duodenal ulcer; but due to their multiplicity and bigger sizes were either resected or diverticulectomies were done anticipating their potential of becoming complicated.

Depending on the indications, we did: In 4 (16.67\%)

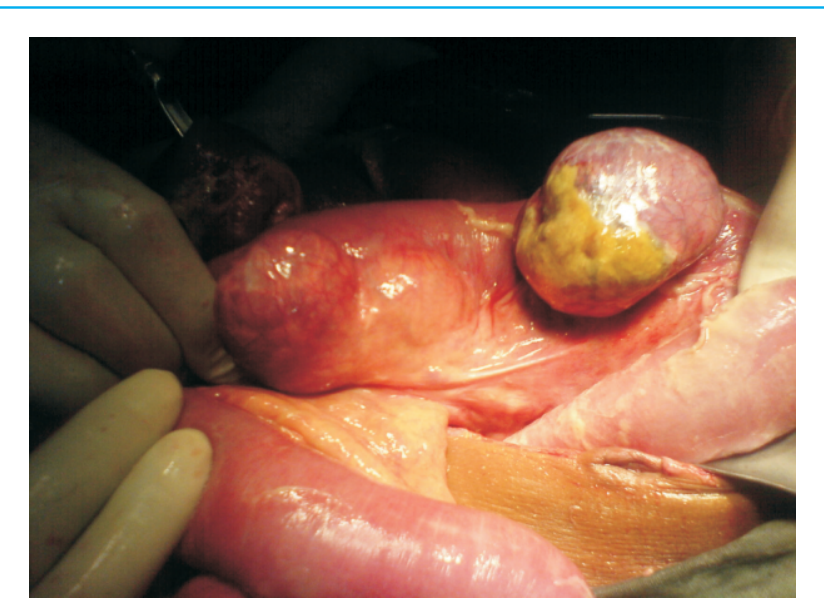

Fig.1: Jejuna diverticuli-patient had volvulus of small intestine around one diverticulum waith a fibrous band

patients, the diverticulae (3 duodenal \& 1 ileal ) were left as such which were asymptomatic and were found as concurrent pathology along with other pathologies. Two patients had congenital bands associated and was the actual cause of obstruction and were excised; while one had omental phlegmon and underwent cholecystectomy; and last one had tuberculous stricture causing obstruction and underwent resection of ileum and primary anastomosis. In 3 (12.5\%) patients, simple excision of diverticulae at the neck without opening the lumen of intestine. In 12 (50\%) formal diverticulectomy and repair of intestine transversely as the diverticulae were solitary as in case of meckel's diverticulum or well spaced multiple jejunal diverticuli to preserve length of intestine. In 5 (20.8\%) patients, multiple diverticulae in jejunum were found with narrow distance in between, resection of the involved segment of intestine and primary end to end anastomosis was done.( Fig 2)

All the patients were put to routine follow-up. Mean hospital stay after surgical procedures was 8 days. Mean duration of follow-up was 15 months.

One patient out of 4 excisions of diverticulum had developed localized abscess in the right iliac region which has to be drained under ultrasonographic control. The patients having omental phlegmon and 


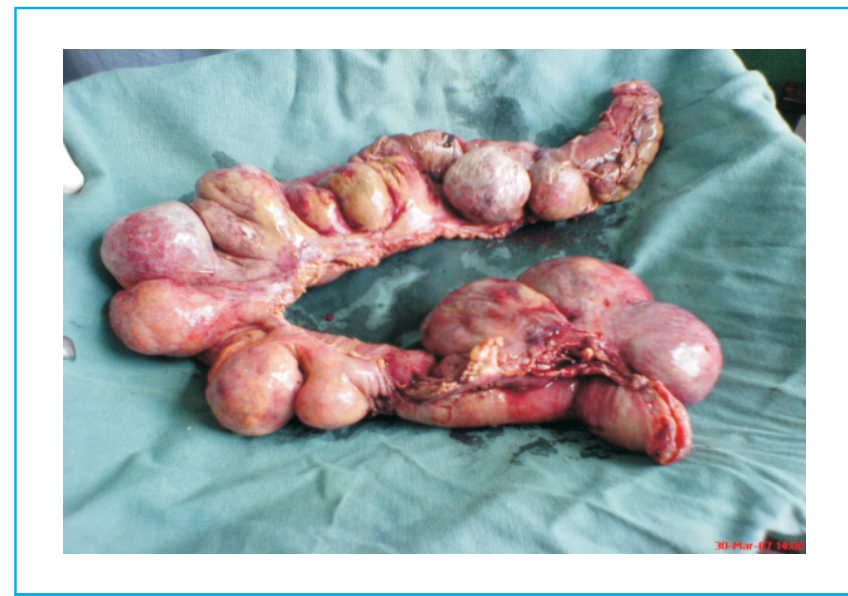

Fig.2: Properative ultrasonography and CT scad did not give a proper diagnosis and exploratory laparotomy revealed multiple giant jejunal diverticula causing intestinal obstruction.

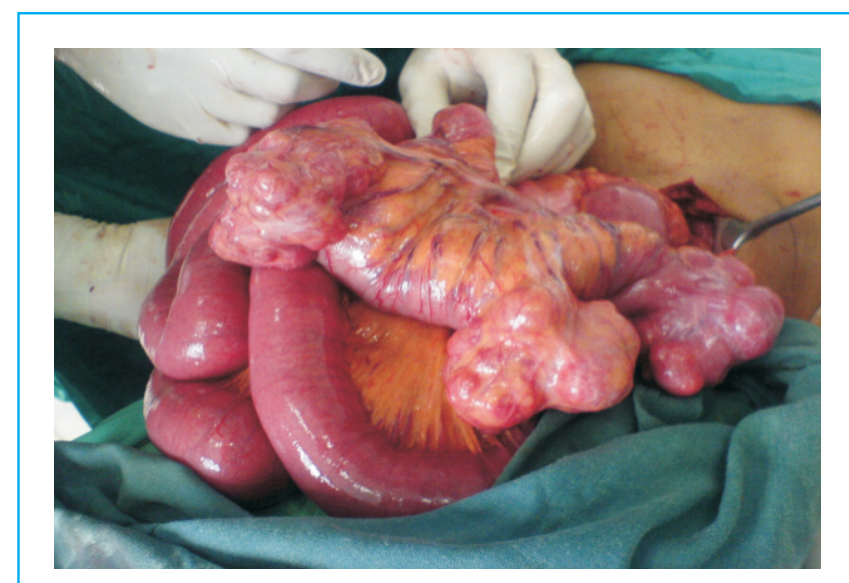

Fig.3: Multiple jejunal diverticuli- the patient presented with a mass in left hypochondrium and investigations could not determine its definite origin preoperatively

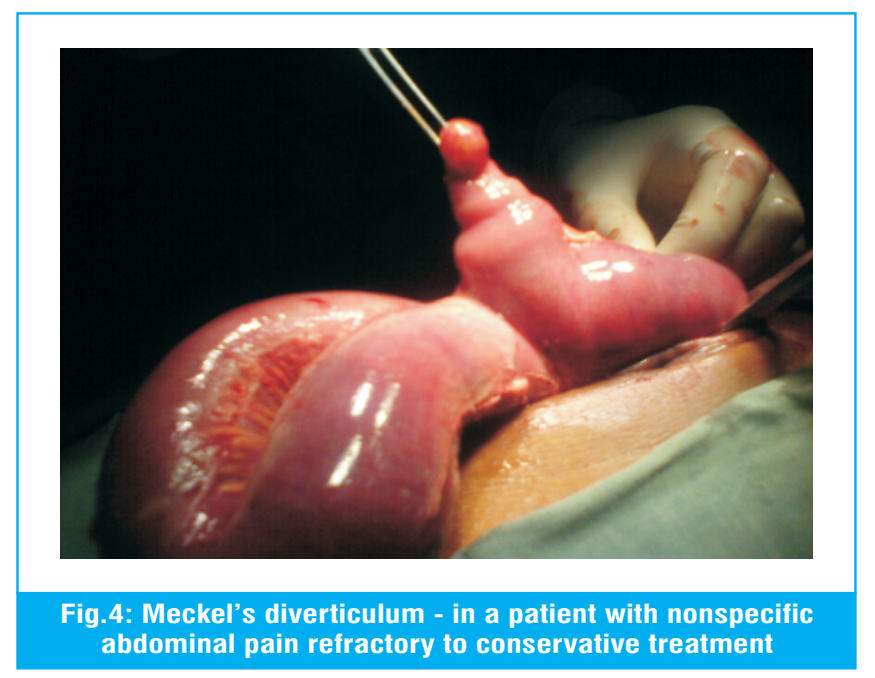

\begin{tabular}{|l|c|}
\hline Excision of diverticulum & $3(12.5 \%)$ \\
\hline Diverticulectomy and primary repair of defect & $12(50 \%)$ \\
\hline Resection and primary anastomosis & $5(20.8 \%)$ \\
\hline No procedure for asymptomatic diverticuli & $4(16.67 \%)$ \\
\hline \multicolumn{2}{|c}{ Table-III. Operative procedures } \\
\hline
\end{tabular}

concurrent duodenal diverticulum developed wound infection leading to readmission for wound toilet and parenteral antibiotics. No patient required reoperation and there was no mortality.

All specimens were sent for histopathology and malignancy or tuberculosis was not reported. Arteriovenous malformation was reported in one specimen with multiple diverticulae; this patient was followed for almost 15 months and remained symptomfree. All 8 Meckel' diverticuli were true diverticuli while all the jejuna and ileal diverticuli were having structure of false diverticuum i.e. composed of mucosa and serosa only and lacking in muscular layers.

\section{DISCUSSION}

Diverticulosis of the jejunum and ileum is an uncommon entity, with a reported prevalence on conventional barium studies of $0.3 \%-1.9 \%$ and at autopsy of $0.3 \%-1.3 \%$ as projected by Schloericke $E$ et al $^{12}$. In our study, the overall incidence of small bowel diverticulosis was $9.2 \%$. While the duodenal diverticuli were $1 \%$ whereas those were having a frequency of approximately $5 \%$ in the study by Rodriguez $\mathrm{HE}^{13}$ et al and Greenstein $S$ et $\mathrm{al}^{14}$. They are less common in the ileum. The highest incidence of jejunal diverticula is in the elderly occurring during the sixth and seventh decades of life (Macari M et al ${ }^{15}$.); Ileal diverticuli which we came across were in fifth decade.

In present study, all the diverticuli were diagnosed intraoperatively; same finding was highlighted in the study by Schloericke E et. al. ${ }^{12}$ which concluded that jejunal diverticulitis is often first diagnosed intraoperatively despite extensive preoperative 
diagnostics.

Haemorrhage as a presenting symptom occurs in $3.4 \%-8.1 \%$ of patients with this condition as cited in the study of Yaqub $S$ et. al ${ }^{16}$.; we came across one case of bleeding per rectum caused by arteriovenous malformations in the jejuna diverticuli i.e $4 \%$.

Mechanical obstruction can be caused by adhesions or stenosis due to diverticulitis, intussusception at the site of the diverticulum and volvulus of the segment containing the diverticula; this was stated in the study by Falidas $E$ et al ${ }^{17}$, similarly our patients presenting with intestinal obstruction had adhesions between diverticuli and small intestinal loops and volvulus in one patient.

Operative procedure carried as transverse diverticulum resection and segment resection should be based on the extent of jejunal diverticulosis and general intraoperative findings ; this also goes with the study by Schloericke $E$ et al $^{12}$ similarly we had diverticulectomies as well as resection of involved intestine in multiple diverticuli.

Obvious perforation, bleeding, or mechanical complications require resection with primary anastomosis. A dilated, hypertrophied segment of jejunum with large diverticula, which indicates a progressive diverticular disease, which is found coincidentally at laparotomy should also be resected; this surgical approach was adopted by McCourtneya $\mathrm{JS}$ et al ${ }^{18}$; similarly we carried resections of silent ileal diverticuli being multiple and bigger in size.

Duodenal diverticula are approximately 5 times more common than jejunoileal diverticula. The actual incidence of both types of diverticula is not known because these lesions are usually asymptomatic ${ }^{1}$. In present study, we encountered 3 duodenal diverticuli and all were silent and coincidental findings.

In Ross CB et. al ${ }^{19}$.and Durai R et. al. ${ }^{20}$ study diverticuli presented with complications like perforation, peritonitis, bleeding, and fistula formation ; similarly our patients presented with obstruction, perforation, peritonitis and bleeding.

The higher incidence as is in our study can be explained on following grounds.

1. The study included only the patients who were harbouring some pathology so is the difference with the incidence of general population or of autopsy findings.

2. We included patients who were symptomatic i.e. having some complications as well as those patients who were otherwise asymptomatic as regards diverticulosis.

3. In the region of Sialkot; due to dietary habits of being more towards nonvegetarian, generally the population is obese/ overweight (anthropometric consideration), which is an accepted fact to be one of the eitiologic factor.

\section{CONCLUSIONS}

Diverticular disease of small intestine is potentially serious, though uncommon. Its complications are considered important cause of intestinal obstruction and acute abdomen and should not be overlooked especially in elderly patients. It must be considered in the differential diagnosis when even the most reliable investigations like CT scan may not give a preoperative diagnosis especially areas like Sialkot, where the prevalence of disease is more as compare to international figures.

This pathology should be considered when the diagnosis is problematic and the signs do not go with the symptoms.. Although it may not be at the top of a differential diagnosis.

\section{Contribution to authorship}

Dr Ansar Latif and Dr Anila Ansar collected all the data and formally conducted the study, Dr Muhammad Qasim Butt planned the study design and gave guide 
lines to conduct it and finalized it. All authors reviewed and approved the final version of the manuscript.

\section{Acknowledgments}

I acknowledge the role of Dr Asad Farhan who guided and helped in collecting references I for this study. I am also thankful to Dr Kashif Abbas who physically spent time and collected the medical record of the patients and completed relevant information in the proformas.

\section{Copyright@ 27 Apr 2013.}

\section{REFERENCES}

1. Belgaumkar A, Karamchandani D, Peddu P and Schulte KM. Small bowel haemorrhage associated with partial midgut malrotation in a middle-aged man. World Journal of Emergency Surgery 2009, 4:1

2. Hamid UI, Khattak S. Bleeding small bowel diverticulosis. Br Med J Case Reports 2009;

3. Alam, Shabbir, Bobby, Manoj DV, Balu K. Intestinal obstruction due to multiple jejunal diverticula. Indian Journal of Surgery; Aug2005, Vol. 67(4): 224.

4. Chugay, Choi PA, Dong JA, Xiang Da. Jejunal diverticular disease complicated by enteroliths: Report of two different presentations. World journal of gastrointestinal surgery 2010.

5. Colvin HS, Kuenfoo C, Rajab TK and Sayadatas T. Nonsurgical management of recurrent perforation of a jejunal diverticulum following previous segmental bowel resection: a case report. Journal of Medical Case Reports 2009, 3:7318.

6. Singh 0, Gupta S, Shukla S, Mathur R K, Shukla S. Jejunal diverticulae: reports of two cases with review of literature. Indian Journal of Surgery 2009 Vol. 71(5): 238-244.

7. Balducci G, Dente M, G, Mercantini P, and Salvi PF. Multiple giant diverticula of the foregut causing upper gastrointestinal obstruction. World J Gastroenterol. 2008 May 28; 14(20).

8. Jeffrey K, Lee, Carethers JM, and Ghosh P. ArterioVenous Malformation within Jejunal
Diverticulum: An Unusual Cause of Massive Gastrointestinal haemorrhage. Gastroenterology Research and Practice. Volume 2009; 4.Case Report.

9. King A, Peters CJ, Shorvon P. Acute pancreatitis with pancreatic abscess secondary to sealed jejunal diverticular perforation. $\mathrm{Br}$ Med $\mathrm{J}$ Case Reports 2012;

10. Tayeb M, Khan FM, Rauf F and Khan MM. Phytobezoar in a jejunal diverticulum as a cause of small bowel obstruction: a case report. Journal of Medical Case Reports 2011; 5:482.

11. Gotian A and Katz S, "Jejunal diverticulitis with localized perforation and intramesenteric abscess," American Journal of Gastroenterology 1998; 93(7):1173-1175.

12. Schloericke E, Zimmermann MS, Hoffmann M, Kleemann M, Laubert $T$, Bruch $H$, Hildebrand $P$. Complicated jejunal diverticulitis: A challenging diagnosis and difficult therapy. Saudi J Gastroenterol 2012;18:122-8

13. Rodriguez HE, Ziauddin MF, Quiros ED, Brown AM, and Podbielski FJ, "Jejunal diverticulosis and gastrointestinal bleeding," Journal of Clinical Gastroenterology 2001; 33:(5):412-414.

14. Greenstein S, Jones B, Fishman EK, Cameron JL, and Siegelman SS, "Small-bowel diverticulitis: CT findings," American Journal of Roentgenology 1986;147(2):271-274.

15. Macari M, Faust M, Liang $\mathrm{H}$, and Pachter HL, "CT of jejunal diverticulitis: imaging findings, differential diagnosis, and clinical management," Clinical Radiology 2007; 62, (1);73-77.

16. Yaqub S, Evensen BV and Kjellevold K. Massive rectal bleeding from acquired jejunal diverticula. World Journal of Emergency Surgery 2011, 6:17.

17. Falidas E, Vlachos K Mathioulakis S, Archontovasilis $\mathrm{F}$ and Villias C. Multiple giant diverticula of the jejunum causing intestinal obstruction: report of a case and review of the literature. World Journal of Emergency Surgery 2011, :8. 
18. McCourtneya JS, Karimb S, Rahillyb M, Dallinga R. Fatal complication of coincidental operative finding. Postgrad Med J 1999;75:625-627.

19. Ross CB, Richards WO, Sharp KW, Bertram PD, and Schaper PW, "Diverticular disease of the jejunum and its complications," American Surgeon
20. Durai $R$, Sinha $A$, Khan $M$, Hoque $H$, and Kerwat $R$. Ruptured Jejunal Diverticulum Due to a Single-Band Small Bowel Obstruction the scientific world journal 2008; 8: 934-940.

\section{AUTHOR(S):}

1. DR. ANSAR LATIF

MBBS, FCPS

Assistant Professor

Department of Surgery

Islam Medical College, Sialkot, Pakistan.

2. DR. ANILA ANSAR

MBBS, MCPS, FCPS

Assistant Professor

Department of Obstetrics and Gynaecology

Islam Medical College, Sialkot, Pakistan.

3. COL. DR. MUHAMMAD QASIM BUTT

MBBS, FCPS

Department of Surgery

Combined Military Hospital, Kohat, Pakistan.
Article received on: 14/03/2013 Accepted for Publication: 27/04/2013 Received after proof reading: 21/09/2013

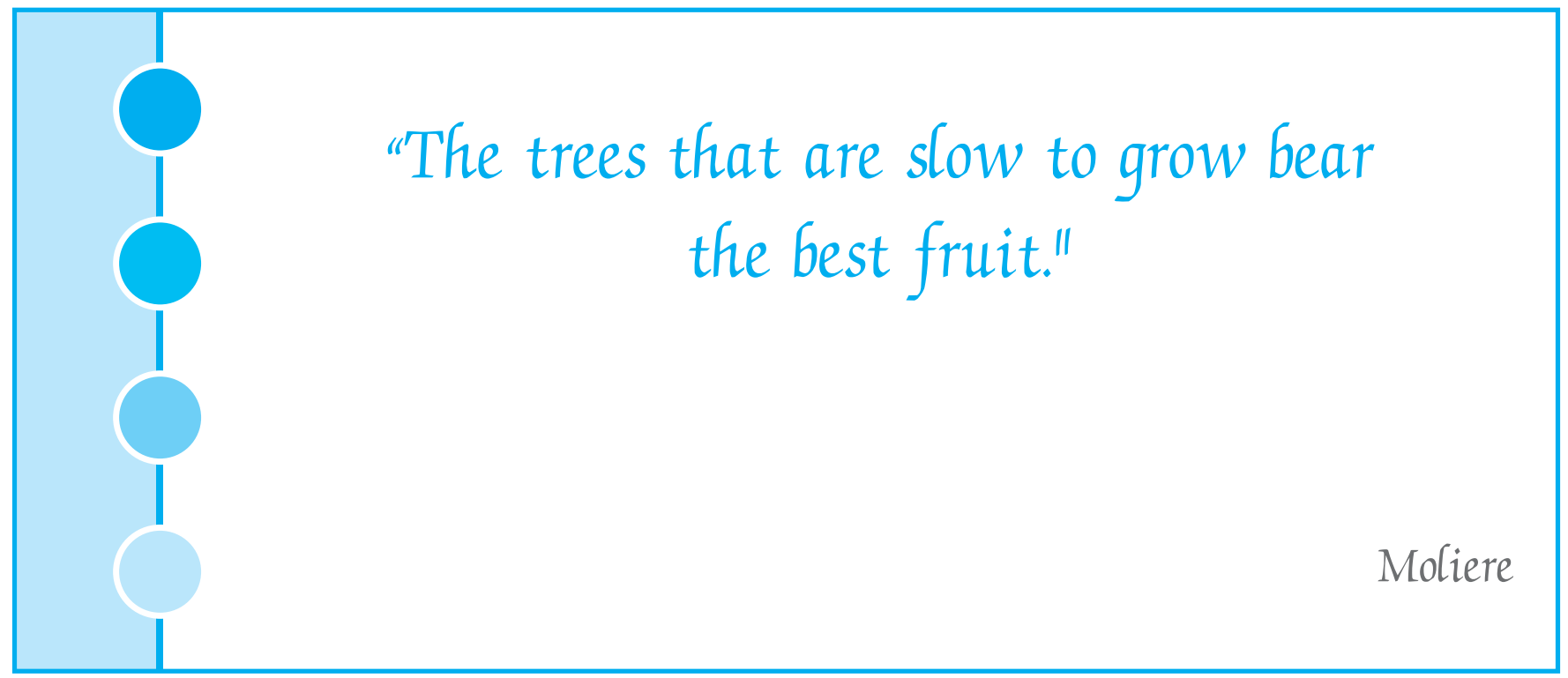

